\title{
Energetic consequences of field body temperatures in the green iguana.
}

Citation for published version (APA):

van Marken Lichtenbelt, W. D., \& Vogel, J. T. (1997). Energetic consequences of field body temperatures in the green iguana. Ecology, 78(1), 297-307. https://doi.org/10.1890/0012-

9658(1997)078[0297:ECOFBT]2.0.CO;2

Document status and date:

Published: 01/01/1997

DOI:

10.1890/0012-9658(1997)078[0297:ECOFBT]2.0.CO;2

Document Version:

Publisher's PDF, also known as Version of record

Document license:

Taverne

Please check the document version of this publication:

- A submitted manuscript is the version of the article upon submission and before peer-review. There can be important differences between the submitted version and the official published version of record.

People interested in the research are advised to contact the author for the final version of the publication, or visit the DOI to the publisher's website.

- The final author version and the galley proof are versions of the publication after peer review.

- The final published version features the final layout of the paper including the volume, issue and page numbers.

Link to publication

\footnotetext{
General rights rights.

- You may freely distribute the URL identifying the publication in the public portal. please follow below link for the End User Agreement:

www.umlib.nl/taverne-license

Take down policy

If you believe that this document breaches copyright please contact us at:

repository@maastrichtuniversity.nl

providing details and we will investigate your claim.
}

Copyright and moral rights for the publications made accessible in the public portal are retained by the authors and/or other copyright owners and it is a condition of accessing publications that users recognise and abide by the legal requirements associated with these

- Users may download and print one copy of any publication from the public portal for the purpose of private study or research.

- You may not further distribute the material or use it for any profit-making activity or commercial gain

If the publication is distributed under the terms of Article $25 \mathrm{fa}$ of the Dutch Copyright Act, indicated by the "Taverne" license above, 


\title{
ENERGETIC CONSEQUENCES OF FIELD BODY TEMPERATURES IN THE GREEN IGUANA
}

\author{
Wouter D. van Marken Lichtenbelt, ${ }^{1} \mathrm{Jacob}^{\mathrm{T}}$. Vogel, ${ }^{2}$ and Renate A. Wesselingh ${ }^{2}$ \\ Carmabi Foundation, P.O. Box 2090, Curaçao, Netherlands Antilles, and \\ Behavioural Biology, University of Groningen, P.O. Box 14, 9750 NN Haren, The Netherlands
}

\begin{abstract}
We investigated body temperatures of free-ranging green iguanas (Iguana iguana) on Curaçao (Netherlands Antilles), and how metabolic costs and benefits of food processing affect body temperatures. Body temperatures of free-living iguanas were measured by radio telemetry. We also used a model, with activity data and operative temperature from taxidermic mounts as inputs, to estimate body temperature of free-ranging animals. Estimated body temperature was highly correlated with telemetered body temperature (mean difference $0.8^{\circ} \mathrm{C}$ ). Thus, our model for estimating lizard body temperatures may be useful in field studies where telemetry is not possible.

Data from both telemetry and estimation with the model showed that green iguanas maintained relatively constant body temperatures (minimum $32.9 \pm 1.4^{\circ} \mathrm{C}$; maximum 36.6 $\pm 2.9^{\circ} \mathrm{C}$; mean $\pm 1 \mathrm{SD}$ ) during the midday period (0945-1545). Temperature measurements of taxidermic mounts and ambient air showed that body temperatures between $29^{\circ} \mathrm{C}$ and $40.5^{\circ} \mathrm{C}$ could readily be attained on Curaçao. Hence, the range of potential body temperatures was much greater than the range of actually achieved body temperatures.

Thermoregulatory behavior, food intake, and locomotor activities were recorded along with temperature measurements. Relations between body temperature, daily metabolizable energy intake (MEI), and resting metabolic rate (RMR) were used to examine whether or not observed body temperatures coincide with temperatures at which energy gain from ingested food is high. Our data show that, in these herbivorous reptiles, food intake and digestion explain most of the variation in the observed field body temperatures.
\end{abstract}

Key words: energetics; field body temperature; Iguana iguana; lizard; operative environmental temperature; temperature telemetry; thermoregulation.

\section{INTRODUCTION}

Diurnal lizards are well known to precisely regulate their body temperature $\left(T_{\mathrm{b}}\right)$ during their daily activity period, despite fluctuating ambient temperatures (Cowles and Bogert 1944). Presumably, thermoregulation not only serves to avoid lethal or damaging temperature extremes, but also to maximize the time spent at optimal temperatures (Cowles and Bogert 1944, Dawson 1975). Although the optimal temperatures for many functions fall in the range of selected body temperatures in the field (Dawson 1975, Huey 1982, Stevenson et al. 1985), there are indications that others do not. For example, some reptiles select higher temperatures after feeding (Cowles and Bogert 1944, Schall 1977, Huey 1982), or spend more time basking after feeding (Hammond et al. 1988), suggesting that digestion may require higher temperatures than do other functions.

Manuscript received 18 November 1994; revised 27 January 1996; accepted 28 February 1996.

${ }^{1}$ Present address: Human Biology, Maastricht University, P.O. Box 616, 6200 MD Maastricht, The Netherlands.

${ }^{2}$ Present address: Institute for Systematics and Population Biology, University of Amsterdam, Kruislaan 318, 1098 SM Amsterdam, The Netherlands.
Superimposed on physiological optima of some functions, physiological and ecological constraints can have a substantial impact on the costs and benefits of maintaining a particular body temperature. Metabolic rate, for example, is related to body temperature (Moberly 1968, Bennett and Dawson 1976), and lizards may sometimes select low temperatures to conserve energy (Regal 1966, Christian et al. 1984).

Many ecologically relevant processes may play a role in balancing the costs and benefits at selected field body temperatures. In thermal studies, properties such as stamina, maximal sustainable speed, or maximum oxygen consumption have received much attention (John-Alder and Bennett 1981, Van Berkum et al. 1986, Huey et al. 1989b), whereas fewer studies have compared other vital processes with selected body temperatures (Huey 1982, Stevenson et al. 1985, Huey et al. 1989a). For example, food digestion may be of crucial importance, especially in herbivorous reptiles, because digestion of plant material is often relatively time consuming. Some studies have indicated that dry matter digestibility is positively related to body temperature (Harlow et al. 1976, Kaufmann and Pough 1982, Troyer 1987). However, other studies that used food intake rates more typical of field conditions have shown a significant influence of body temperature on the tran- 
sit rate of food through the digestive tract rather than on digestibility (Parmenter 1981, Zimmerman and Tracy 1989, van Marken Lichtenbelt 1992). Although an inverse relation between body temperature and gut passage time has been demonstrated in these studies, the metabolic costs and benefits associated with optimal temperatures for food digestion remain to be investigated and compared to the costs at actual field body temperatures.

Besides the energetic costs and benefits linked to body temperature, it is relevant to know whether or not animals are able to select optimal body temperatures in their habitat. Thermal constraints can arise because the body temperature of an ectotherm is a complex function of its biology and its biophysical environment (Gates 1980). These constraints may be measured by comparing the pattern of thermal microclimate availability with the use of microclimate by lizards (Christian et al. 1983). Operative environmental temperature $\left(T_{\mathrm{e}}\right)$ has been developed as a thermal index of microclimate (Bakken and Gates 1975, Bakken 1976, 1992 , Bakken et al. 1985). $T_{\mathrm{e}}$ may be defined as the temperature of an inanimate object of zero heat capacity with the same size, shape, and radiative properties as the animal exposed to the same microclimate. For an ectothermic reptile, with no pelage, $T_{\mathrm{e}}$ is the environmental temperature as experienced by the animal, and is an index of the thermal potential driving heat flow. $T_{\mathrm{e}}$ can be measured directly for many species of reptiles using taxidermic mounts (Bakken et al. 1985).

We performed a study on green iguanas (Iguana iguana) on the tropical island Curaçao. We collected data on $T_{\mathrm{e}}$ using taxidermic mounts, and on $T_{\mathrm{b}}$ by estimation and telemetry. The following questions were addressed: (1) What are the potentially available field body temperatures for green iguanas? (2) Which are the actually achieved field body temperatures? (3) What relationships might exist between field body temperatures and the metabolic costs and benefits for food processing of those body temperatures?

\section{Methods}

\section{Climate and study site}

The study was conducted from August 1987 until April 1988 at Santa Barbara on Curaçao, Netherlands Antilles. Curaçao has a semiarid climate with strong spatial and seasonal variation in rainfall. Mean annual yrainfall is $570 \mathrm{~mm}$, to which the rains in OctoberJanuary contribute $64 \%$, with considerable year-to-year variation. Monthly mean air temperature is $27.5^{\circ} \mathrm{C}$, with a minimum of $25.3^{\circ} \mathrm{C}$ in January and a maximum of $30.9^{\circ} \mathrm{C}$ in September. Strong trade winds blow from the east nearly all year round (mean wind speed 7.1 $\mathrm{m} / \mathrm{s}$ ). Seasonality of the rainfall has a strong influence on plant production and, thus, on food for the iguanas, often resulting in a period of low food availability from February to June (van Marken Lichtenbelt 1993). The

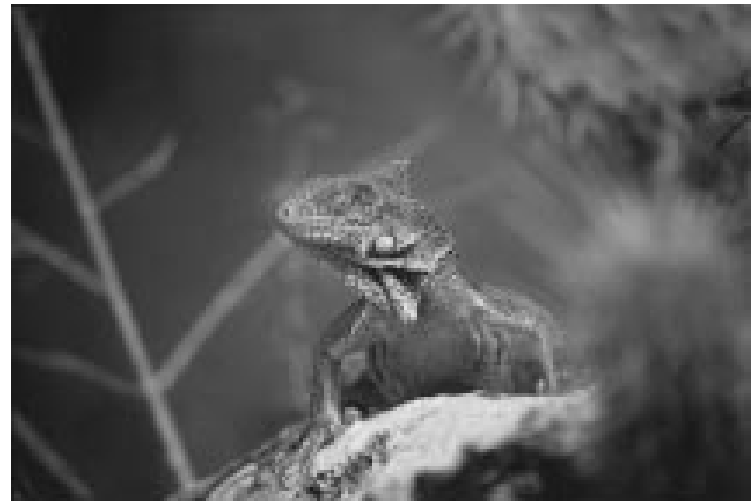

Plate 1. Contrary to arboreal mainland populations, in many areas on Curaçao the green iguanas live on rocks, making use of trees only for foraging.

reproductive cycle is geared to this seasonality (van Marken Lichtenbelt and Albers 1993). The mating season takes place from March to April. Eggs are laid in April-May, and hatching takes place in the second half of July and August.

The study site encompassed $\approx 0.7$ ha with large limestone boulders, situated in front of a limestone plateau. The boulders were partly covered with shrubs, cacti, and small trees. The intervening areas were densely vegetated with trees, shrubs, and various climbing plants.

\section{Observations}

Five blinds surrounding the main observation rocks were constructed. Four blinds stood on the edge of the plateau and one on top of a large rock. Most of the day, the iguanas stayed on the rocks and only went into the vegetation to feed. There they tended to forage in the top layer of the trees and shrubs. Due to the high position of the blinds, it was possible to observe individual iguanas throughout their daily activity periods. Observations with a telescope from blinds (one person per blind) were made by two to three persons who communicated by radio. Animals were recognized by individual characteristics of the tail, dewlap, and crest prior to their eventual capture. Colored beads were attached to the crest of all captured individuals so that identification could be made more rapidly. The iguanas with temperature transmitters were followed daily during three observation periods of 2-3 wk each: AugustSeptember 1987, December-January 1987/1988, March-April 1988. Observations took place from 30 min after sunrise until sunset. Only whole-day observations, with continuous behavioral records, were used for analyses. During the same periods, other iguanas on the study site were observed for whole days in rotation. No extreme weather conditions were observed during these observation periods.

The following data relevant to body temperature were recorded every $5 \mathrm{~min}$ for the focal animals: 
1) the animal's location;

2) the substrate used: rock or shrub/tree;

3) the animal's posture: body and head in full contact with the substrate, body flat but head up, body semi-upright, or body upright;

4) the animal's position relative to the sun. The "sphere" of possible radiation angles around the animal was divided into five classes. The angle of radiation was "rostral" when the rays made an angle of $<45^{\circ}$ with the longitudinal (snout-to-tail) axis of the animal. The part of this cone-shaped region with angles $<10^{\circ}$ was called "extremely rostral." Radiation with incoming angles between $135^{\circ}$ and $180^{\circ}$ with this axis was called "caudal." The remaining "saddle"-like part of the sphere was divided into two classes, depending on the angle with the second, dorsal-ventral, axis, perpendicular to the first. Radiation with an angle $<45^{\circ}$ with this second axis was "dorsal," and the remainder was "lateral";

5) the percentage of the body exposed to the sun;

6) the animal's wind exposure: no wind $(W=0)$; crest and/or dewlap move due to the wind $(W=2)$; dewlap, crest, and head move $(W=3)$. In the period March-April 1988, we attached a $3 \mathrm{~cm}$ long cotton thread to the crest, just behind the animal's head, to refine the wind exposure measurement. If the thread only was moving, it was classified as $W=1$.

The following data relevant to the time budget were also registered every $5 \mathrm{~min}$ : (1) movement $(>30 \mathrm{~cm}$, about one body length) since the preceding record; and (2) locomotor activities: total time spent walking on the rock, and time spent sprinting. These were calculated from mean walking and sprinting speeds and distance covered in $5 \mathrm{~min}$. The mean walking and sprinting speeds were calculated from previous, direct observations in which distance and time taken for walking or sprinting had been recorded (van Marken Lichtenbelt et al. 1993).

Foraging time was obtained from continuous observations and was defined as the sum of minutes in which eating actually occurred. For comparison among individuals, we used only results from those animals for which at least three complete observation days were available. Metabolizable energy intake (MEI, $\left.\mathrm{kJ} \cdot \mathrm{kg}^{-1} \cdot \mathrm{d}^{-1}\right)$ is determined by direct complete-day observations on food intake, chemical analyses of available food types, and digestion trials (van Marken Lichtenbelt 1992). The number of bites taken could be converted to biomass and MEI, as described in van Marken Lichtenbelt (1993).

\section{Telemetry}

Body temperatures of three free-living green iguanas were successfully measured using radio telemetry, during different observation periods for 14,16 , and $8 \mathrm{~d}$, respectively (Tables 1 and 2). An animal was caught at its sleeping site, taken to the laboratory, and weighed. The next morning, it was anesthetized by in-
TABLE 1. Characteristics of the iguanas under study, as measured when caught just before the start of an observation period. Each individual is identified by a two-letter code.

\begin{tabular}{llcrrl}
\hline \hline Code & Season & Sex & $\begin{array}{c}\text { SVL } \dagger \\
(\mathrm{cm})\end{array}$ & $\begin{array}{c}\text { Mass } \\
(\mathrm{g})\end{array}$ & $\begin{array}{l}\text { Source of } \\
\text { temperature data }\end{array}$ \\
\hline GO & Aug-Sep & $\mathrm{f}$ & 32.5 & 1328 & telemetry \\
BG & Dec-Jan & f & 29.3 & 902 & telemetry \\
BG & Mar-Apr & f & 28.9 & 805 & model estimation \\
LB & Mar-Apr & m & 28.0 & 695 & telemetry \\
PB & Mar-Apr & m & 27.8 & 628 & model estimation \\
LY & Mar-Apr & m & 30.5 & 815 & model estimation \\
LL & Mar-Apr & f & 27.5 & 783 & model estimation \\
\hline
\end{tabular}

$\dagger$ Snout-vent length.

traperitoneal injection of $0.8 \mathrm{~mL} / \mathrm{kg}$ Ketamine. Temperature-sensitive transmitters $(2.5 \times 1.7 \times 0.8 \mathrm{~cm}$, OM1 of the AVM Instrument Company) with the thermistor mounted on the end of a $6-8 \mathrm{~cm}$ long medical-grade silicone probe (diameter $1.5 \mathrm{~mm}$ ) were used. The transmitter was taped laterally to the tail near the base, and the probe was subcutaneously led to the abdomen. A small incision was made in skin and peritoneum so that the tip of the probe $(1.5 \mathrm{~cm})$ could be led into the abdominal cavity. The abdominal skin incision was then sutured. After sunset, the animal was released at the capture site. We had observed each animal several days prior to capture; we saw no obvious differences in behavior after implantation, although female BG seemed to be more wary.

The transmitter generated pulses wherein the interval between pulses varied inversely with temperature. Every 15 min during daytime, pulse frequency was measured by counting pulses in 2 min (receiver: AVM LA12-DS). Occasionally, nighttime body temperatures were measured. After a 2-3 wk period of continuous observation, the animal was recaptured and the transmitter was removed. Upon inspection, all telemetered animals were in good condition and no infection was evident. The next day, after another visual inspection of the incision and the general appearance, the animals were released at the place of capture. Transmitters were calibrated, using a waterbath and thermometer, before and after the experiments (accuracy $\pm 0.1^{\circ} \mathrm{C}$ ).

\section{Estimating body temperature}

Two hollow, copper replicas of the green iguana were constructed (snout-vent lengths (SVL) $30 \mathrm{~cm}$ and 25 $\mathrm{cm}$, the range of SVLs of live iguanas under study) out of copper sheet ( $\approx 0.5 \mathrm{~mm}$ thick). They closely matched the lizards' actual shape, including legs and tail. A thermistor was located inside the models. The mounts could be filled with water to obtain a heat capacity similar to that of live animals. We used empty mounts for measuring the consequences of being in a particular environment (see Appendix). The copper models were covered with skins of iguanas. After sewing up the edges, we allowed the skins to dry. During drying, the 
TABLE 2. Actual and simulated iguana body temperatures $\left({ }^{\circ} \mathrm{C}\right.$, mean $\left.\pm 1 \mathrm{SD}\right)$ during the day, night, 24-h, and midday periods; modal day, minimum, and maximum field body temperatures. Also given are water-filled mount $\left(T_{\mathrm{m}}\right)$ and air temperatures.

\begin{tabular}{|c|c|c|c|c|c|c|c|c|c|c|c|}
\hline \multirow[b]{2}{*}{$\mathrm{Coc}$} & \multirow[b]{2}{*}{ Method } & \multirow[b]{2}{*}{ Sex } & \multirow[b]{2}{*}{ Period } & \multicolumn{8}{|c|}{ Body temperature $\left({ }^{\circ} \mathrm{C}\right)$} \\
\hline & & & & Day & Night & 24-h & $\begin{array}{l}\text { Mode } \\
\text { (day) }\end{array}$ & $\begin{array}{l}\text { Maxi- } \\
\text { mum } \\
\text { (night) }\end{array}$ & $\begin{array}{l}\text { Mini- } \\
\text { mum }\end{array}$ & Midday & $n$ \\
\hline \multicolumn{12}{|c|}{ A) Field body temperatures } \\
\hline GC & telemetry & $\mathrm{f}$ & Aug-Sep & $35.6 \pm 1.5$ & $29.3 \pm 1.1$ & 31.9 & $36-37$ & 42.9 & 24.5 & $36.6 \pm 1.4$ & 14 \\
\hline $\mathrm{BC}$ & telemetry & $\mathrm{f}$ & Dec-Jan & $34.7 \pm 1.4$ & $29.3 \pm 0.6$ & 31.4 & $36-37$ & 41.8 & 25.8 & $36.0 \pm 1.5$ & 16 \\
\hline LB & telemetry & $\mathrm{m}$ & Mar-Apr & $33.9 \pm 1.3$ & $27.2 \pm 0.5$ & 29.9 & $35-36$ & 43.1 & 26.0 & $35.3 \pm 1.6$ & 8 \\
\hline LB & simulated & $\mathrm{m}$ & Mar-Apr & $33.1 \pm 0.8$ & & 29.6 & $34-35$ & 40.0 & 26.5 & $34.7 \pm 1.2$ & 8 \\
\hline $\mathrm{PB}$ & simulated & $\mathrm{m}$ & Mar-Apr & $33.3 \pm 1.1$ & & 29.7 & $34-35$ & 41.0 & 26.5 & $35.0 \pm 1.2$ & 2 \\
\hline LY & simulated & $\mathrm{m}$ & Mar-Apr & $32.8 \pm 0.7$ & & 29.5 & $32-33$ & 40.1 & 25.2 & $34.7 \pm 0.9$ & 7 \\
\hline LL & simulated & $\mathrm{f}$ & Mar-Apr & 32.8 & & 30.7 & $34-36$ & 36.6 & 26.5 & 34.5 & 1 \\
\hline $\mathrm{BC}$ & simulated & $\mathrm{f}$ & Mar-Apr & $31.2 \pm 1.0$ & & 28.8 & & 37.7 & 25.1 & $32.9 \pm 1.2$ & 3 \\
\hline \multicolumn{12}{|c|}{ B) Model and air temperatures } \\
\hline$T_{\mathrm{m}}$ & & & Aug-Sep & $38.9 \pm 1.5$ & & & $42-43$ & 53.5 & 24.5 & $40.6 \pm 2.3$ & 14 \\
\hline $\mathrm{Ai}$ & & & Aug-Sep & $29.9 \pm 1.7$ & $28.1 \pm 0.5$ & & & 33.6 & 24.8 & $37.7 \pm 2.0$ & 14 \\
\hline$T_{\mathrm{m}}$ & & & Dec-Jan & $38.3 \pm 1.8$ & & & $39-40$ & 47.8 & 25.8 & $41.5 \pm 0.9$ & 16 \\
\hline $\mathrm{Ai}$ & & & Dec-Jan & $28.1 \pm 1.2$ & $26.8 \pm 0.5$ & & & 30.5 & 24.1 & $28.8 \pm 1.4$ & 16 \\
\hline$T_{\mathrm{m}}$ & simulated & & Mar-Apr & $38.6 \pm 1.5$ & & & $38-40$ & 48.9 & 26.5 & $40.7 \pm 2.1$ & 8 \\
\hline $\mathrm{Ai}$ & & & Mar-Apr & $28.8 \pm 0.6$ & $26.3 \pm 0.3$ & & & 31.2 & 24.5 & $29.7 \pm 0.6$ & 8 \\
\hline
\end{tabular}

skins shrank slightly, producing a snug fit between skin and copper. There was no apparent change in color during drying, although a change in near-IR reflectance may have been possible. As a result, the models were good replicas of live iguanas and, because the skins were intact, they possessed virtually the same radiation absorptivity and thermal emissivity as the skin of live iguanas, as shown for mammal and bird pelage by Bakken and Gates (1975).

The taxidermic mounts were used to measure the operative environmental temperature $\left(T_{\mathrm{e}}\right)$ in the field (see Appendix). The $T_{\mathrm{e}}$ of models in locations and body positions similar to those of free-ranging lizards could be used to estimate the body temperature of iguanas for which no telemetry data were available, if detailed behavioral observations were made (for calculations, see Appendix). The body temperature estimation was validated against $3 \mathrm{~d}$ of body temperature measured by telemetry. We used the calibrated model to estimate body temperatures of five animals for $8,2,7,1$, and 3 d (Table 2). Tables 1 and 2 and Figs. 5 and 6 indicate whether the data are derived from telemetered or estimated temperatures.

Air temperature was measured every 15 min during observation periods, using a thermistor located $1 \mathrm{~m}$ above a shaded rock patch under a naturally shaped rock cover exposed to wind.

\section{RESULTS}

\section{General basking behavior}

Green iguanas on the study site lived on large, limestone boulders in small groups composed of a dominant adult male with one or more adult females, and often accompanied by one or more subadults of either sex. The night was spent on steep walls, in shrubs, or in crevices. At, or shortly after, local sunrise, most lizards moved to basking places located at variable distances (1-20 m) from their sleeping sites. Most basking places combined sun exposure with a wide view over the area, and often were close to hiding places. Lizards basked for $\geq 3 \mathrm{~h}$, after which they usually went foraging in vegetation surrounding the rocks. Most green iguanas foraged once or twice per day for $\approx 0.5-1.5 \mathrm{~h}$, but did not forage every day. During the hottest part of the day $(\approx 1300-1600)$, they were often seen under shrubs or in an upright position on wind-exposed places. Shortly after sunset, the iguanas returned to their sleeping sites.

\section{Estimated body temperatures}

Comparisons of measured body temperatures of a radio-tracked green iguana (LB) and its estimated body temperature show that, in most circumstances, the estimated temperatures approached the actual measured temperature closely (Fig. 1A, B and Appendix). In some cases, by the end of the day, the estimated body temperature dropped below the measured body temperature (Fig. 1C). This was probably due to the influence of the substrate temperature. In these cases, the animals adpressed their body against the warm substrate, something we could not mimic with the copper models. Temperature measurements indicated that the stone surface at the end of the day can exceed $45^{\circ} \mathrm{C}$. Effective substrate temperatures were hard to quantify, because the irregular shape of the rocks at the study site causes many different exposure positions. We conclude that our procedure provides a reasonable estimate 


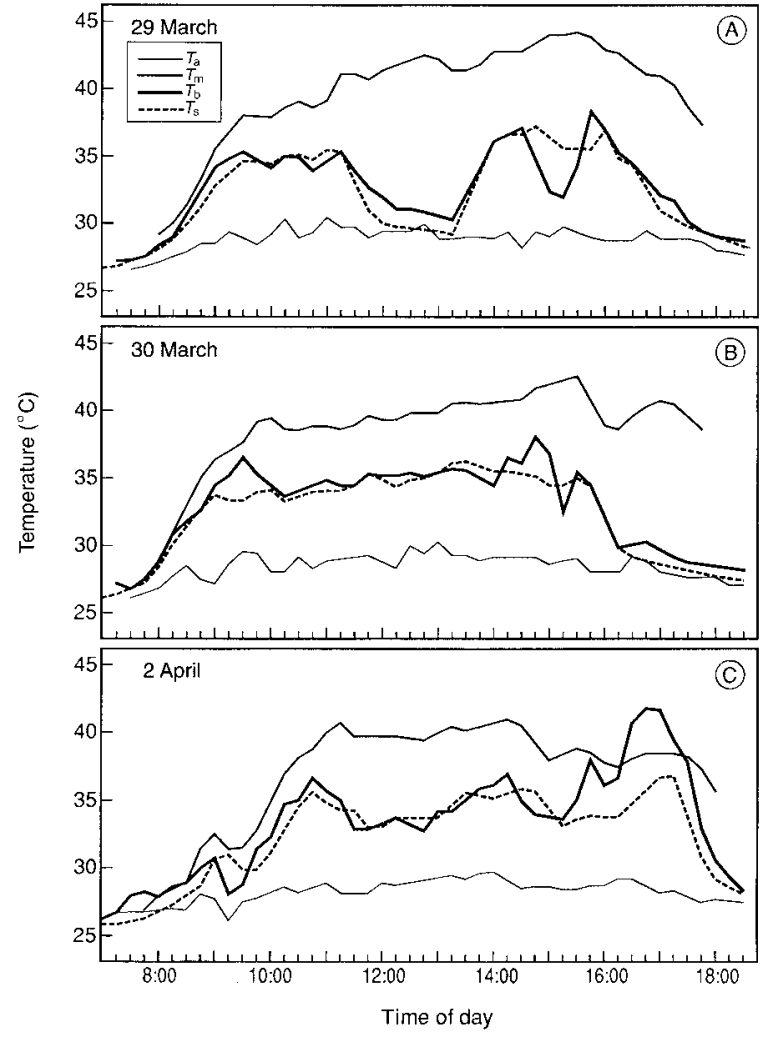

FIG. 1. Body temperature $\left(T_{\mathrm{b}}\right)$ of a single green iguana (animal LB), air temperature $\left(T_{\mathrm{a}}\right)$, maximal potential body temperature $\left(T_{\mathrm{m}}\right)$, and the estimated body temperature $\left(T_{\mathrm{s}}\right)$ during the course of the day, for three days.

of the measured body temperature, except when substrate temperature accounts for a relatively large proportion of the total heat flow to the animal's body (see Bakken 1989).

\section{Field body temperature in the course of a day}

Body temperature profiles of telemetered lizards show four distinct phases during $24 \mathrm{~h}$ (Fig. 2): (1) early morning: warming up; (2) midday (0945-1545): relatively stable temperatures; (3) late afternoon: much variation in body temperatures, including cooling after local sunset (standard deviations are significantly larger than in preceding periods, $F$ test); (4) night: body temperatures close to air temperature; in crevices, $T_{\mathrm{b}}$ is $0.5^{\circ}-1^{\circ} \mathrm{C}$ higher than air temperature.

During the early morning, water-filled mount temperatures were comparable to the iguana's $T_{\mathrm{b}}$ (Fig. 1), but the mount reached mean midday values of $40.0^{\circ} \mathrm{C}$ and $39.2^{\circ} \mathrm{C}$, whereas the iguana's mean midday temperatures were $33.8^{\circ} \mathrm{C}$ and $35.3^{\circ} \mathrm{C}$. This demonstrates that the iguanas potentially can reach much higher temperatures than they actually achieve. Mean day and midday body temperatures of all animals were always below those of the water-filled mount (Table 2).

\section{Actual and potential body temperature}

Comparison of the frequency distributions of daytime body temperature and the potential maximal body temperature ( $T_{\mathrm{m}}$, water-filled mount) of male LB shows that mean $T_{\mathrm{b}}\left(33.9^{\circ} \mathrm{C}\right)$ and modal $T_{\mathrm{b}}\left(35^{\circ}-36^{\circ} \mathrm{C}\right)$ were much lower than the values of $T_{\mathrm{m}}$ (mean: $38.6^{\circ} \mathrm{C}$; modal: $38^{\circ}-40^{\circ} \mathrm{C}$; Fig. 3 ). At midday (taking temperature values from 1100 to 1430 ), the modal body temperature was equal to whole-day values, but the frequency distribution was symmetric due to absence of the warming up and cooling down periods. During midday, $50 \%$ of the body temperatures fell between $34.0^{\circ}$ and $37.0^{\circ} \mathrm{C}$.

In the iguanas for which estimated or telemetered data from $>6 \mathrm{~d}$ were available (GO, BG, LB, and LY; Table 2), the frequency distributions of the midday body temperatures were not significantly skewed, except for male LY (skewness, $g_{1}=-0.56, P<0.05$; Sokal and Rohlf 1981). If we exclude from analysis one day when male LY had an unusually long stay in a crevice, this frequency distribution is also not significantly skewed. Midday body temperatures for all individuals had a minimum standard deviation of $1.4^{\circ} \mathrm{C}$ and a maximum of $2.9^{\circ} \mathrm{C}$, indicating the narrow range of body temperatures. Body temperatures during midday were analyzed for each individual by one-way ANOVA to determine day-to-day differences in body temperatures. All individuals for which enough data were available $(n=5)$ had significant $(P<0.05)$ vari-
FIG. 2. Mean 15 -min body temperature $( \pm 1$ SD) during the course of the day for male iguana LB. Telemetry results from $7 \mathrm{~d}$ in the period March-April 1988.

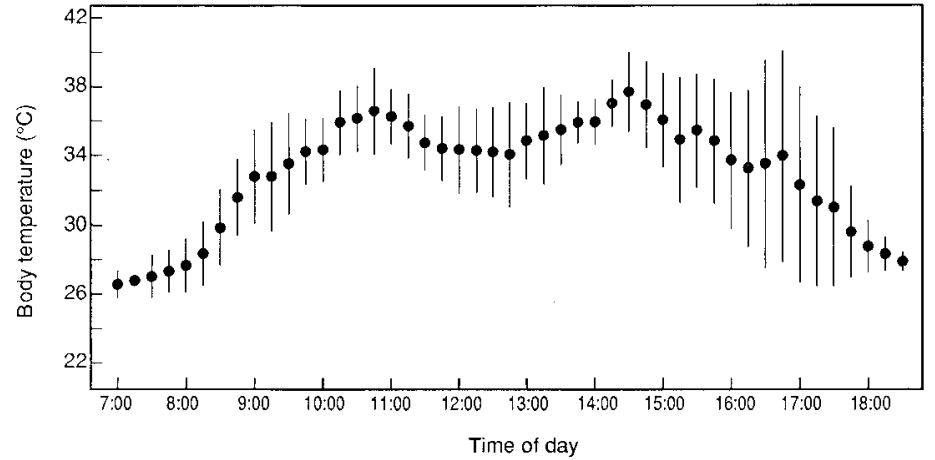




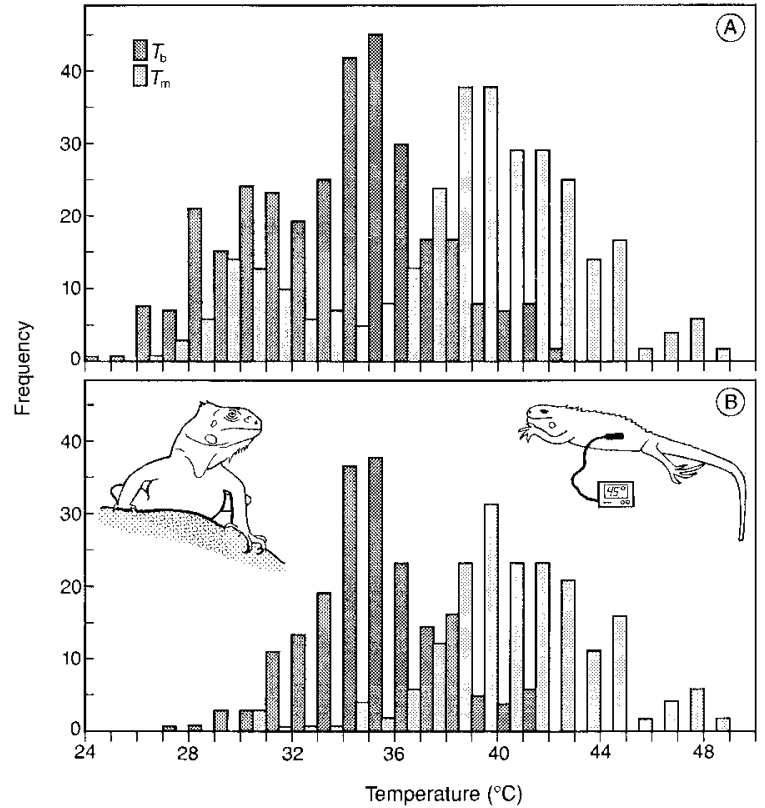

FIG. 3. Frequency distributions of daytime (A) and midday (B) telemetered body temperatures $\left(T_{\mathrm{b}}\right)$ of male LB and the potential maximal body temperature $\left(T_{\mathrm{m}}\right)$. Frequency distribution during midday (0945-1545) is more symmetric, due to the absence of periods of warming in the morning and cooling in late afternoon. $N=8$ observation days.

ation among days with respect to midday body temperatures.

\section{Activities linked to locomotion}

The data presented here are from outside the mating season. There were no significant differences in distances covered between "mating period" and "nonmating period" (van Marken Lichtenbelt et al. 1993). The time spent locomoting and foraging contributed almost all $(>95 \%)$ of the daily activity time. Time spent moving differed between the sexes. Males spent a mean $23.1 \mathrm{~min} / \mathrm{d}$ moving, vs. $13.6 \mathrm{~min} / \mathrm{d}$ for females (Table 3 ). Iguanas moved for $\approx 45 \%$ of the distance covered on horizontal to moderately sloping, very irregular rock surface, whereas $25 \%$ of the distance was covered by climbing up and down steep slopes and vertical escarpments. The remaining distance $(30 \%)$ was tra- versed in shrubs and trees. Time devoted to vigorous sprinting was a mean $0.19 \mathrm{~min} / \mathrm{d}$ in males. On 20 of the $33 \mathrm{~d}$ of observation, sprinting occurred. Sometimes considerable distances $(>20 \mathrm{~m})$ were covered during a chase.

\section{Metabolizable energy intake}

Daily metabolizable energy intake (MEI) of the green iguanas varied greatly among individual iguanas (Table 4). Female BG did not forage for $6 \mathrm{~d}$ in MarchApril, whereas female GO had a mean MEI of 49.3 $\mathrm{kJ} \cdot \mathrm{kg}^{-1} \cdot \mathrm{d}^{-1}$ in August-September (van Marken Lichtenbelt et al. 1993).

\section{DISCUSSION Body temperature}

Green iguanas encounter relatively stable air temperatures on Curaçao. Both trade winds and cloudy intervals make it possible for iguanas to pick locations where they can maintain observed body temperature ranges. During prolonged rainy periods (several days), however, body temperatures may drop below those levels, which may have a substantial negative impact on the lizard's energy expenditure and food intake (W. D. van Marken Lichtenbelt, personal observation, on captive population)

Mean daytime body temperatures found in this study are comparable to body temperatures found in other studies on green iguanas (Table 5). Midday body temperatures reported from other iguanines are also of the same level as the green iguanas on Curaçao, although Cyclura nubia (Christian et al. 1986) and particularly the desert iguana Dipsosaurus dorsalis $\left(40^{\circ}-42^{\circ} \mathrm{C}\right.$, DeWitt 1967) have higher body temperatures.

\section{Estimating body temperatures}

Taxidermic mounts are frequently used to compare actual body temperatures with potential body temperatures (Grant and Dunham 1988, Huey et al. 1989b, Grant 1990) or to explain basking behavior (Crawford et al. 1983, Hammond et al. 1988). Our method used the model in a fixed orientation towards sun and wind, in a fixed microclimate type from which the temperatures in other types and in other orientations could be estimated. This has the advantage that the temperature

TABLE 3. Daily distances covered and time spent on locomotor activities by male and female green iguanas; values are mean \pm 1 SD. Differences between males and females are tested with unpaired $t$ tests.

\begin{tabular}{llll}
\hline \hline \multicolumn{1}{c}{ Locomotor activity } & \multicolumn{1}{c}{ Males $\dagger$} & \multicolumn{1}{c}{ Females $\$$} & \multicolumn{1}{c}{$t$ test } \\
\hline Distance moved on rock (m/d) & $57.9 \pm 6.0$ & $34.4 \pm 3.4$ & $P<0.01$ \\
Distance moved in vegetation (m/d) & $19.3 \pm 3.7$ & $15.3 \pm 6.4$ & NS \\
Time spent locomoting (min/d) & $23.1 \pm 2.6$ & $13.6 \pm 1.5$ & $P<0.01$ \\
Time spent foraging (min/d) & $14.3 \pm 6.1$ & $16.0 \pm 4.2$ & NS \\
Time spent sprinting (min/d) & $0.19 \pm 0.11$ & $0.01 \pm 0.01$ & $P<0.01$ \\
\hline
\end{tabular}

$\dagger n=3$ males observed; total observation period $=33 \mathrm{~d}$

$\ddagger n=4$ females observed; total observation period $=58 \mathrm{~d}$.

$\S$ For each statistic in this table, df $=89$. 
TABLE 4. Metabolizable energy intake, MEI $\left(\mathrm{kJ} \cdot \mathrm{kg}^{-1} \cdot \mathrm{d}^{-1}\right.$, mean $\pm 1 \mathrm{SD}$ ), estimated from observations of bites taken during entire days, for green iguanas whose field body temperatures were measured simultaneously over $N$ days (see Table 3).

\begin{tabular}{llllr}
\hline \hline Code & Period & Sex & MEI & $N(\mathrm{~d})$ \\
\hline GO & Aug-Sep & $\mathrm{f}$ & $49.3 \pm 35.0$ & 22 \\
BG & Dec-Jan & $\mathrm{f}$ & $13.2 \pm 23.6$ & 22 \\
LB & Mar-Apr & $\mathrm{m}$ & $29.1 \pm 21.6$ & 19 \\
LY & Mar-Apr & $\mathrm{m}$ & $15.0 \pm 13.9$ & 8 \\
PB & Mar-Apr & $\mathrm{m}$ & $21.7 \pm 19.9$ & 7 \\
LL & Mar-Apr & $\mathrm{f}$ & $38.8 \pm 18.3$ & 6 \\
BG & Mar-Apr & $\mathrm{f}$ & 0 & 6 \\
\hline
\end{tabular}

measurements of the mounts can be used to obtain estimates of both potential maximum body temperatures and transient body temperatures. Moreover, only one mount is necessary to predict body temperatures of several animals (depending on the number of animals that can be observed in detail).

However, heating and cooling results may differ from models to live animals, because of color changes. Lizard color changes may be related to the control of heat gain from visible and near-infrared radiation (Rice and Bradshaw 1980, Bartholomew 1982), and may be important for large ectotherms (Stevenson 1985). Indeed, iguanas on Curaçao tended to be darker in early morning than during midday (W. D. van Marken Lichtenbelt, personal observations). Heating and cooling of lizards may also differ due to adjustments of blood circulation. A living animal cools more slowly than it warms up, and both cooling and warming are slower in dead bodies (Bartholomew and Vleck 1979, Bartholomew 1982). Notwithstanding the possible sources of error, the method is accurate within $1{ }^{\circ} \mathrm{C}$ (see Appendix) when estimates of mean body temperatures over a period of several hours or longer are desired. Our discussion centers on these long-term values, and we feel our approach is adequately accurate.
Costs and benefits associated with body temperature

Food passage in the green iguana is an important temperature-dependent process. Therefore, we compared field body temperatures with optimal temperatures for food processing (i.e., temperatures at which metabolizable energy intake rate minus energy expenditure is maximal). Results from food digestion trials with captive green iguanas showed that the apparent dry matter digestibility was not related to body temperature. However, transit time (TT) of food through the intestinal tract proved to be significantly inversely related to body temperature (van Marken Lichtenbelt 1992): with increasing $T_{\mathrm{b}}$, food processing is increased. The same study revealed that the ad libitum maximal rate of fresh-food intake was linearly related to the transit time.

Combining these relations with the metabolizable energy content of the food gives the relation between the potential metabolizable energy intake (MEI) and body temperature $\left(T_{\mathrm{b}}\right)$ : $\mathrm{MEI}_{\max }=132.0-4085 \times$ $10^{-0.06} T_{\mathrm{b}}$, MEI in kilojoules per kilogram per day (Fig. 4). Resting metabolic rate (RMR) is related to $T_{\mathrm{b}}$ as follows (van Marken Lichtenbelt et al. 1993): RMR = $2.22 \times 10^{0.036 T_{\mathrm{b}}}($ Fig. 4).

Combination of the data on $\mathrm{MEI}_{\max }$ and RMR shows a gradual increase in net energy gain $\left(\mathrm{MEI}_{\max }-\mathrm{RMR}\right)$ with rising body temperature until a body temperature of $36.5^{\circ} \mathrm{C}$ is reached (Fig. 4). According to the derived formulas (based on extrapolation from a temperature range of $30.0^{\circ}-36.5^{\circ} \mathrm{C}$ for $\mathrm{MEI}_{\max }$ ), net energy gain decreases above $36.5^{\circ} \mathrm{C}$. This temperature coincides with the upper end of the range of recorded mean midday body temperatures $\left(36.6^{\circ} \mathrm{C}\right)$. Clearly, more data are necessary over a wider temperature range with different foods. Nevertheless, our data indicate that the observed body temperatures coincide with, or are below, the derived optimal $T_{\mathrm{b}}$ for food processing.

In the cost-benefit model presented, the costs of for-

TABLE 5. Field body temperatures of iguanines.

\begin{tabular}{llccc}
\hline \hline \multirow{2}{*}{\multicolumn{1}{c}{ Species }} & \multicolumn{1}{c}{ Place } & \multicolumn{2}{c}{ Body temperature $\left({ }^{\circ} \mathrm{C}\right)$} & Refer- \\
\cline { 3 - 5 } ence $\dagger$ \\
\hline Amblyrhynchus cristatus & Galápagos Islands & $35-37$ & Day & 1 \\
Cylura nubia & Puerto Rico & & $37.9-39.4$ & 2 \\
Conolophus pallidus & Galápagos Islands & & $36.4-37.6(\mathrm{~m} \ddagger)$ & 2 \\
& & & $35.2-37.0(\mathrm{f} \ddagger)$ & 2 \\
Dipsosaurus dorsalis & California & & 42 & 3 \\
Iguana iguana & Costa Rica & $34.0-37.2$ & & 4 \\
& Mexico & $31-39$ & & 5 \\
& Colombia & $33.8-40.6$ & \\
Sauromalus obesus & Curaçao & $31.2-35.6$ & $32.9-37.8$ & 7 \\
& South West USA & & $35-37$ & 8 \\
& California & & $36.6-39.6$ & 9 \\
\hline
\end{tabular}

$\dagger$ References: 1, Bartholomew 1966; 2, Christian et al. 1986; 3, DeWitt 1967; 4, Hirth 1963; 5, McGinnis and Brown 1966; 6, Müller 1972; 7, this study; 8, Zimmerman and Tracy 1989;

9, Muchlinski et al. 1990.

\$ m, male; f, female. 


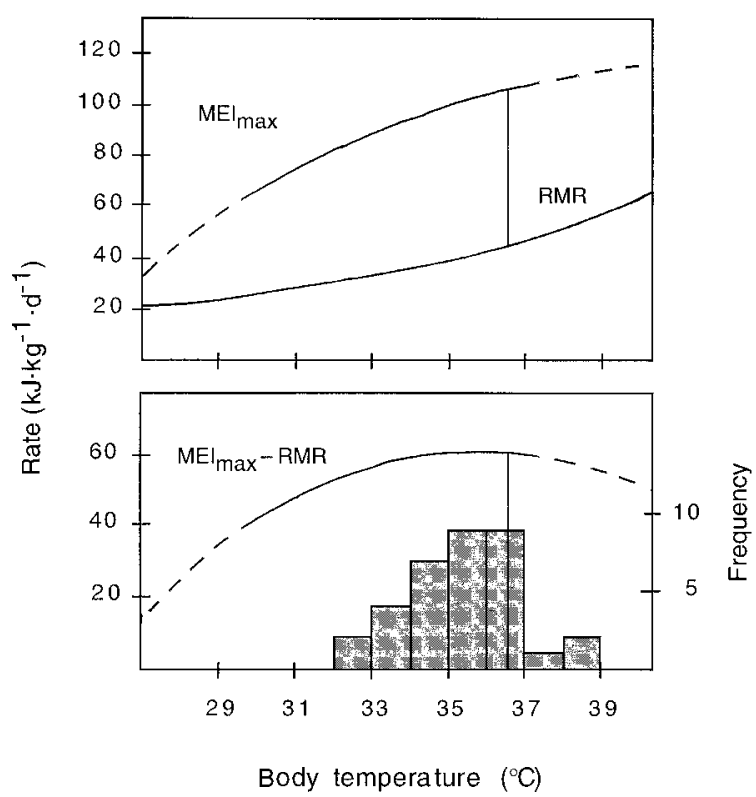

FIG. 4. Resting metabolic rate (RMR), maximal metabolizable energy intake $\left(\mathrm{MEI}_{\max }\right)$, and the difference between $\mathrm{MEI}_{\max }$ and RMR as functions of body temperature in Iguana iguana. The gray area indicates the range of observed mean midday field body temperatures. Vertical lines indicate the maximal differences between $\mathrm{MEI}_{\max }$ and RMR.

aging are not incorporated. Although free-living iguanas do not cover large distances, the costs of transport are substantial (van Marken Lichtenbelt et al. 1993), involving mainly strenuous climbing. If the investment in obtaining the maximum amount of food is too high (e.g., when food availability is low), it is beneficial to consume less food. In that case, it would be energetically advantageous to select a lower body temperature, corresponding to the amount eaten (see Fig. 4). Indeed, midday field body temperature is significantly positively related to the daily metabolizable energy intake (Fig. 5). Since transit times are $\geq 3 \mathrm{~d}$, we also calculated MEI over longer periods ( $\geq 6 \mathrm{~d}$ ). After removing one significant outlier (animal BG from September; Bonferroni-corrected outlier test), the relation between mean 24-h $T_{\mathrm{b}}$ and mean MEI is highly significant ( $P$ $<0.001$; Fig. 6). The green iguana GO had the highest MEI of the animals examined, and had a mean midday body temperature of $36.6^{\circ} \mathrm{C}$ (Table 2). It is interesting to note that body temperatures of Conolophus pallidus were also significantly lower during the season with relatively low food availability, although higher body temperatures potentially could have been obtained (Christian and Tracy 1985).

Walking at regular speed may affect $T_{\mathrm{b}}$, especially since costs of locomotion due to climbing on steep walls and in vegetation are high (van Marken Lichtenbelt 1993). The relation between the time spent moving and $T_{\mathrm{b}}$ is not significant. However, stepwise forward multiple regression ( $F \geq 4$ to add, $F \leq 3.99$ to remove)

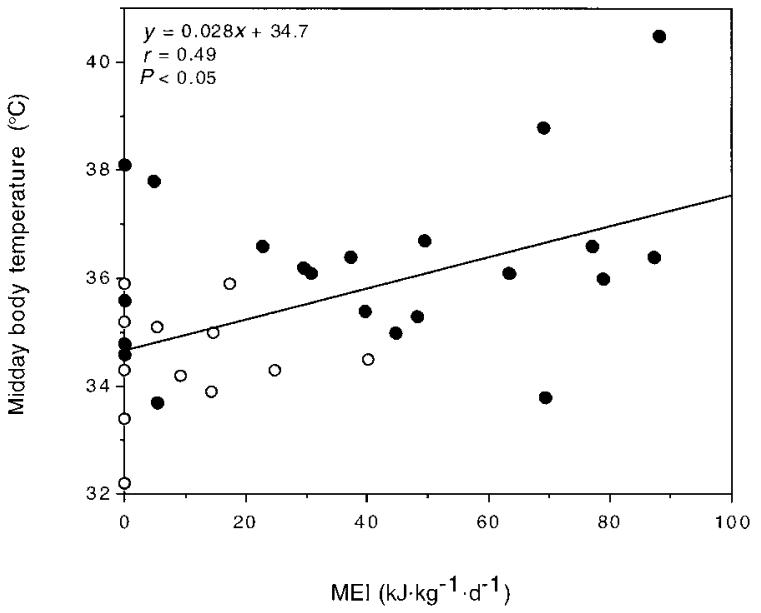

FIG. 5. Midday body temperatures (6-h mean) of free-living green iguanas in relation to their daily metabolizable energy intake (MEI). Solid circles are telemetered data; open circles are model estimations.

showed that adding distance moved while climbing, distance moved in a horizontal plane, and distance moved in vegetation to the regression of $T_{\mathrm{b}}$ and MEI improved the fit. MEI alone gave a multiple correlation coefficient of $R=0.96$ and a standard error of estimate (SEE) of 0.33 (Fig. 6), whereas inclusion of the distances resulted in $R=1.0$ and $\mathrm{SEE}=0.02$. All variables had positive regression coefficients. Food intake (expressed in MEI) and locomotion thus seem to explain most of the variation in field body temperature. This line of thought about the thermal sensitivity of locomotion is still speculative, and direct measurements on the thermal dependence of stamina are badly needed.

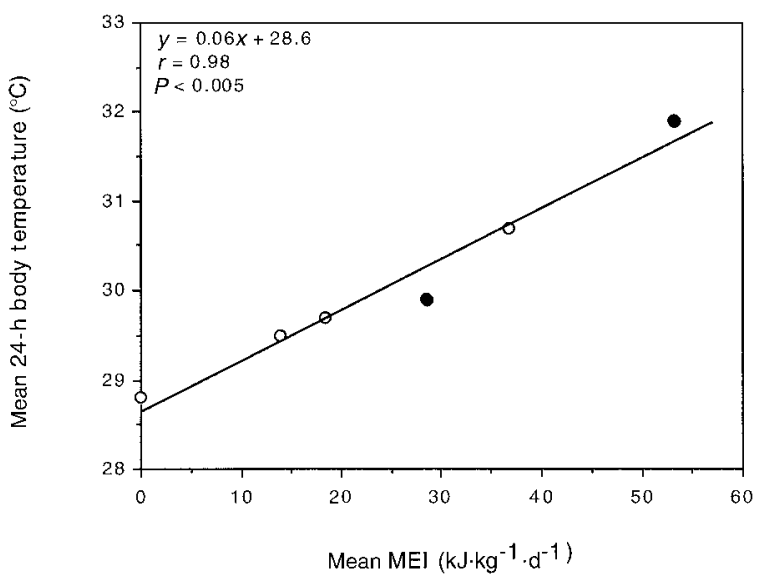

FIG. 6. Mean 24-h body temperatures of free-living green iguanas in relation to their mean daily metabolizable energy intake (MEI), both averaged over $\geq 6 \mathrm{~d}$. Solid circles are telemetered data; open circles are model estimations. 


\section{ACKNOWLEDGMENTS}

We thank Walter Bakhuis, director of the Carmabi Foundation, for his support during the study. Many thanks go to the personnel of Carmabi for their cooperation, in particular to Aubrey Tiel. The Mining Company, Curaçao kindly gave us permission to work on their property. Assistance in the field from Martin Brinkhof, Jan Drent, and Rudi Drent is much appreciated. Miriam Criens obtained many of the laboratory temperature data. Iris de Jonge and Olav de Haseth patiently taught us animal surgery. Fred Choemasseru of the Indel Company helped us with designing the electronic devices. Climate data were provided by A. J. Dania of the Meteorological Service, Curaçao. Dick Visser prepared the figures. Koen Albers, Rudi Drent, Aren van Es, Raymond Huey, Kenneth Nagy, and Joe Schall read the manuscript critically and made many valuable suggestions.

\section{Literature Cited}

Bakken, G. S. 1976. A heat-transfer analysis of animals: unifying concepts and the application of metabolism chamber data to field ecology. Journal of Theoretical Biology 60:337-384.

- - 1989. Arboreal perch properties and the operative temperature experienced by small animals. Ecology $\mathbf{7 0}$ 922-930.

1992. Measurement and application of operative and standard operative temperatures in ecology. American Zoologist 32:194-216.

Bakken, G. S., and D. M. Gates. 1975. Heat-transfer analysis of animals: some implications for field ecology, physiology, and evolution. Pages 255-290 in D. M. Gates and R. B. Schmerl, editors. Perspectives of biophysical ecology. Springer-Verlag, New York, New York, USA.

Bakken, G. S., W. R. Santee, and D. J. Erskine. 1985. Operative and standard operative temperature: tools for thermal energetics studies. American Zoologist 25:933-943.

Bartholomew, G. A. 1966. A field study of temperature relations in the Galápagos marine iguana. Copeia 1966:241250 .

- 2 1982. Physiological control of body temperature Pages 25-92 in C. Gans and F. H. Pough, editors. Biology of the Reptilia. Volume 12 (physiology C). Academic Press, New York, New York, USA.

Bartholomew, G. A., and D. Vleck. 1979. The relation of oxygen consumption to body size and to heating and cooling in the Galápagos marine iguana, Amblyrhynchus cristatus. Journal of Comparative Physiology 132:285-288.

Bennett, A. F., and W. R. Dawson. 1976. Metabolism. Pages 127-223 in C. Gans and W. R. Dawson, editors. Biology of the Reptilia. Volume 5 (physiology A). Academic Press, New York, New York, USA.

Christian, K. A., I. E. Clavijo, N. Cordero-Lopez, E. E. EliasMaldonado, M. A. Franco, M. V. Lugo-Ramirez, and M. Marengo. 1986. Thermoregulation and energetics of a population of Cuban iguanas (Cyclura nubila) on Isla Magueyes, Puerto Rico. Copeia 1986:65-69.

Christian, K. A., and C. R. Tracy. 1985. Physical and biotic determinants of space utilization by the Galápagos land iguana (Conolophus pallidus). Oecologia 66:132-140.

Christian, K. A., C. R. Tracy, and W. P. Porter. 1983. Seasonal shifts in body temperature and use of microhabitats by Galápagos land iguanas (Conolophus pallidus). Ecology 64: 463-468.

Christian, K. A., C. R. Tracy, and W. P. Porter. 1984. Physiological and ecological consequences of sleeping-site selection by the Galápagos land iguana (Conolophus pallidus). Ecology 65:752-758.

Cowles, R. B., and C. M. Bogert. 1944. A preliminary study of the thermal requirements of desert reptiles. Bulletin of the American Museum of Natural History 83:261-295.
Crawford, K. M., J. R. Spotila, and E. A. Standora. 1983. Operative environmental temperatures and basking behavior of the turtle Pseudemys scripta. Ecology 64:989-999.

Dawson, W. R. 1975. On the physiological significance of the preferred body temperatures of reptiles. Pages 443-473 in D. M. Gates and R. D. Schmerl, editors. Perspectives of biophysical ecology. Volume 12 (ecological studies). Springer-Verlag, New York, New York, USA.

DeWitt, C. B. 1967. Precision of thermoregulation and its relation to environmental factors in the desert iguana, Dipsosaurus dorsalis. Physiological Zoology 40:49-66.

Gates, D. M. 1980. Biophysical ecology. Springer-Verlag, New York, New York, USA.

Grant, B. W. 1990. Trade-offs in activity time and physiological performance for thermoregulating desert lizards, Sceloporus merriami. Ecology 71:2323-2333.

Grant, B. W., and A. E. Dunham. 1988. Thermally imposed time constraints on the activity of the desert lizard Sceloporus merriami. Ecology 69:167-176.

Hammond, K. A., J. R. Spotila, and E. A. Standora. 1988. Basking behavior of the turtle Pseudemys scripta: effects of digestive state, acclimation temperature, sex, and season. Physiological Zoology 61:69-77.

Harlow, H. J., S. S. Hillman, and N. Hoffman. 1976. The effect of temperature on digestive efficiency of the lizard, Dipsosaurus dorsalis. Journal of Comparative Physiology 111:1-6.

Hirth, H. F. 1963. Some aspects of the natural history of Iguana iguana on a tropical strand. Ecology 44:613-615.

Huey, R. B. 1982. Temperature, physiology, and the ecology of reptiles. Pages 25-92 in C. Gans and F. H. Pough, editors. Biology of the Reptilia. Volume 12 (physiology C). Academic Press, New York, New York, USA.

Huey, R. B., P. H. Niewiarowski, J. Kaufmann, and J. C. Herron. 1989b. Thermal biology of nocturnal ectotherms: is sprint performance of geckos maximal at low body temperatures? Physiological Zoology 62:488-540.

Huey, R. B., C. R. Peterson, S. J. Arnold, and W. P. Porter. 1989a. Hot rocks and not-so-hot rocks: retreat-site selection by garter snakes and its thermal consequences. Ecology 70:931-944.

John-Alder, H. B., and A. F. Bennett. 1981. Thermal dependence of endurance and locomotory energetics in a lizard. American Physiological Society 241:R342-R349.

Kaufmann, R., and F. H. Pough. 1982. The effect of temperature upon the efficiency of assimilation of preformed water by the desert iguana (Dipsosaurus dorsalis). Comparative Biochemical Physiology 72A:221-224.

McGinnis, S. M., and C. W. Brown. 1966. Thermal behavior in the green iguana, Iguana iguana. Herpetologica 22:189199.

Moberly, W. R. 1968. The metabolic responses of the common iguana, Iguana iguana, to activity under restraint. Comparative Biochemical Physiology 27:1-20.

Muchlinski, A. E., J. M. Hogan, and R. J. Stoutenburgh. 1990. Body temperature regulation in a desert lizard, Sauromalus obesus, under undisturbed field conditions. Comparative Biochemical Physiology 95A:579-583.

Müller, H. 1972. Ökologische und ethologische Studien an Iguana iguana L. (Reptilia: Iguanidae) in Kolombien. Zoologische Beiträge 18:109-131.

Parmenter, R. R. 1981. Digestive turnover rates in freshwater turtles: the influence of temperature and body size. Comparative Biochemical Physiology 70A:235-238.

Regal, P. J. 1966. Thermophilic response following feeding in certain reptiles. Copeia 1966:588-590.

Rice, G. E., and S. D. Bradshaw. 1980. Changes in dermal reflectance and vascularity and their effects on thermoregulation in Amphibolurus nuchalis (Reptilia: Agamidae). Journal of Comparative Physiology 135:139-146. 
Schall, J. J. 1977. Thermal ecology of five sympatric species of Cnemidophorus (Sauria: Teiidae). Herpetologica 33: 261-272.

Sokal, R. R., and F. J. Rohlf. 1981. Biometry. The principles and practice of statistics in biological research. Second edition. W. H. Freeman, New York, New York, USA.

Stevenson, R. D. 1985. The relative importance of behavioral and physiological adjustments controlling body temperature in terrestrial ectotherms. American Naturalist 126: 362-386.

Stevenson, R. D., C. R. Peterson, and J. S. Tsuji. 1985. The thermal dependence of locomotion, tongue flicking, digestion, and oxygen consumption in the wandering garter snake. Physiological Zoology 58:46-57.

Troyer, K. 1987. Small differences in daytime body temerature affect digestion of natural food in a herbivorous lizard (Iguana iguana). Comparative Biochemical Physiology 87A:623-626.

Van Berkum, F. H., R. B. Huey, and B. A. Adams. 1986. Physiological consequences of thermoregulation in a trop- ical lizard (Ameiva festiva). Physiological Zoology 59:464472.

van Marken Lichtenbelt, W. D. 1992. Digestion in an ectothermic herbivore, the green iguana (Iguana iguana): effect of food composition and body temperature. Physiological Zoology 65:649-673.

—— 1993. Optimal foraging of a herbivorous lizard, the green iguana, in a seasonal environment. Oecologia 95: 246-256.

van Marken Lichtenbelt, W. D., and K. B. Albers. 1993. Reproductive adaptations of the green iguana on a semiarid island. Copeia 1993:790-798.

van Marken Lichtenbelt, W. D., R. A. Wesselingh, J. T. Vogel, and K. B. M. Albers. 1993. Energy budgets in free-living green iguanas in a seasonal environment. Ecology 74: $1157-1172$.

Zimmerman, L. C., and C. R. Tracy. 1989. Interactions between the environment and ectothermy and herbivory in reptiles. Physiological Zoology 62:374-409.

\section{APPENDIX}

\section{Modelling Body Temperature}

We developed a method to estimate body temperatures of free-living iguanas by using behavioral data in combination with operative temperature measurements. For this, two hollow, empty model iguanas were constructed as operative temperature sensors. One of these was used as a reference for general meteorological conditions, much as a single micrometeorological station might be used. The temperature of the second model was determined relative to the first. The second model was placed in various orientations to the sun, substrate types, wind, and shade. For each of these situations, at least 16 comparisons were made between the two models. A multiple regression was used to generate an empirical model, the dependent variable being the temperature of the second model. The independent variables were all interaction terms between the temperature of the first model and the various observable aspects of posture and exposure to thermal factors of the second model. This gave an estimated operative temperature for any similarly sized iguana whose posture and exposure variables were known. This operative temperature could then be smoothed by an exponential time filter with a time constant derived from cooling curves on the same models (then filled with water) to give an estimated body temperature. The coefficients were later adjusted to fit body temperatures of live iguanas with telemetry transmitters in the field.

The following abbreviations are used:

$T_{\mathrm{b}}=$ body temperature

$T_{\mathrm{e}}=$ operative environmental temperature

$T_{\mathrm{a}}=$ air temperature

$T_{\mathrm{s}}=$ estimated body temperature

$T_{\text {eq }}=$ steady-state temperature of the mount

$T_{\mathrm{ex}}=$ mount temperature during tests at different locations

$\tau=$ time constant

The first empty mount (snout-vent length, SVL $=30 \mathrm{~cm}$ ) was always situated with the ventral side of the body on a flat piece of rock at the same spot, and was constantly kept perpendicular to the sun. In this way, sun exposure was maximal $(100 \%)$ and angle of radiation was dorsal. Wind exposure at the spot was $W=1$. Temperatures of the mount $\left(T_{\mathrm{e}}\right)$ and air $\left(T_{\mathrm{a}}\right)$ were registered every $15 \mathrm{~min}$. An empty mount was used because of the relatively low $\tau$ value, providing accurate measurements of the changes in radiation. The time constant $(\tau)$ from the equation of exponential decay $T_{t}=T_{\mathrm{eq}}+\left(T_{0}-\right.$ $\left.T_{\text {eq }}\right) \times e^{(-t / \tau)}($ Bakken and Gates 1975) is the time required for
$63.2 \%(1-1 / e)$ of the total temperature change to occur. $\tau$ was graphically obtained from the cooling curves of both empty and water-filled models. The models were heated to $45^{\circ} \mathrm{C}\left(T_{0}\right)$ in a free-convection environment and, while located with the ventral side of the body on a polystyrene substrate, were allowed to cool to steady state $\left(T_{\mathrm{eq}}\right) . \tau$ of the empty and water-filled models was 11.5 and $50.5 \mathrm{~min}$, respectively.

The position of the second mount (measuring $T_{\mathrm{ex}}$ ) was varied with respect to substrate (rock or shrub), orientation to the sun's rays (see Methods), and percentage exposed to the sun. From the difference between $T_{\mathrm{e}}$ and $T_{\mathrm{ex}}$, we derived factors $(f)$, expressed relative to $T_{\mathrm{a}}: f=\left(T_{\mathrm{ex}}-T_{\mathrm{a}}\right) /\left(T_{\mathrm{e}}-T_{\mathrm{a}}\right) \times$ $100 \%$. Each experiment was tested four times an hour for at least $4 \mathrm{~h}$. In this way, we included some of the environmental variation in wind speed and solar radiation. During an experiment, the orientation towards the sun was regularly adjusted to keep the solar angle constant. $f$ was obtained by averaging the $f$ values of 15 -min intervals. Wind speed affected both $f$ and $\tau$ values. $f$ and $\tau$ values were adjusted for actual field circumstances using simultaneous measurements of $T_{\mathrm{e}}$ and body temperature and behavioral data from radiotracked male LB (on 28 and 31 March and 6 April), so that the difference between actual and estimated body temperature

TABLE A1. Correction factors $f\left[=\left(T_{\mathrm{ex}}-T_{\mathrm{a}}\right) /\left(T_{\mathrm{e}}-T_{\mathrm{a}}\right) \times\right.$ $100 \%$, and the $\tau$ values (time constants) used to calculate body temperatures from $T_{\mathrm{e}}, T_{\mathrm{a}}$, and the positional protocols of free-living iguanas. The mount was situated on rock, exposed to the sun with a dorsal angle of radiation, and had a wind exposure of $W=1$.

\begin{tabular}{llrc}
\hline \hline \multicolumn{1}{c}{ Exposure } & \multicolumn{1}{c}{ Variables } & $\begin{array}{c}f \\
(\%)\end{array}$ & $\begin{array}{c}\tau \\
(\mathrm{min})\end{array}$ \\
\hline Substrate & rock & 100 & \\
& vegetation & 85 & \\
Angle of radiation $\dagger$ & dorsal & 100 & \\
& lateral & 85 & \\
& rostral & 70 & \\
Wind exposure & extremely rostral & 55 & \\
& $W=0$ & 124 & 30 \\
& $W=1$ & 100 & 30 \\
& $W=2$ & 74 & 20 \\
& $W=3$ & 62 & 10 \\
\hline
\end{tabular}

$\dagger$ Sun relative to body. 
was minimized. The total adjustment was $<3 \%$. The resulting $f$ values and $\tau$ values are presented in Table A1.

For estimation of field body temperatures, $T_{\mathrm{e}}$ was assumed to be the steady-state temperature of the empty mount, and 5 -min values of $T_{\mathrm{a}}$ and $T_{\mathrm{e}}$ were obtained by linear interpolation of the 15-min measurements. The estimated steady-state temperature of the animal under study (equal to $T_{\mathrm{eq}}$ ) was determined by $T_{\mathrm{a}}, T_{\mathrm{e}}$, and the position of the animal:

$$
\begin{gathered}
T_{\text {eq }}=T_{\mathrm{a}}+\left(T_{\mathrm{e}}-T_{\mathrm{a}}\right) \times f_{\text {substrate }} \times f_{\text {angle }} \text { of radiation } \\
\times f_{\text {wind }} \times \% \text { exposed to sun. }
\end{gathered}
$$

The time interval $(t)$ used for iterative calculations was 5 min. At the beginning of this interval $\left(T_{0}\right), T_{\text {eq }}, \tau$, and $t$ were used to calculate the (estimated) body temperature at the end of this interval:

$$
T_{\mathrm{b}}=T_{\mathrm{eq}}+\left(T_{0}-T_{\mathrm{eq}}\right) \times e^{(-t / \tau)} .
$$

Body temperature at the end of the time interval was $T_{0}$ for the next 5-min interval, etc. By repeating this procedure, the body temperatures in the course of the day could be estimated. The procedure started at local sunrise, when air temperature and $T_{\mathrm{e}}$ were equal $\left(T_{0}=T_{\mathrm{a}}=T_{\mathrm{e}}\right)$.

Correlation between actual body temperature and estimated body temperatures was highly significant $(R=0.91, P<$ 0.001 , df $=370)$, and the slope did not deviate significantly from unity (ANCOVA). Although estimated individual temperature values could be off by some degrees, mean estimated values over a period of several hours were close to actual values. Actual mean body temperature was $33.9^{\circ} \mathrm{C}$ vs. a mean estimated temperature of $33.1^{\circ} \mathrm{C}$ (paired $t$ test: $P>0.05$, df $=370)$. The mean midday (0945-1545) body temperature was $35.4^{\circ} \mathrm{C}$ vs. $35.0^{\circ} \mathrm{C}$ (paired $t$ test: $P>0.1$, df $=199$ ). In general, when we used data over a period of $1 \mathrm{~d}$, the method provided good estimates. 